\title{
Epidemiologic and Clinical Characteristics of Cardiomyopathies in Japan Results From Nationwide Surveys
}

\author{
Akira Matsumori, MD; Yutaka Furukawa, MD; Koji Hasegawa, MD; \\ Yukihito Sato, MD; Hideaki Nakagawa, MD*; Yuko Morikawa, MD*; \\ Katsuyuki Miura, MD*; Yoshiyuki Ohno, MD**; Akiko Tamakoshi, MD**; \\ Yutaka Inaba, $\mathrm{MD}^{\dagger}$; Shigetake Sasayama, MD; and Co-research workers ${ }^{\S}$
}

\begin{abstract}
Nationwide clinico-epidemiological surveys of cardiomyopathies in Japan were carried out. Disorders surveyed included idiopathic dilated cardiomyopathy (DCM), hypertrophic cardiomyopathy (HCM), restrictive cardiomyopathy (RCM), arrhythmogenic right ventricular dysplasia (ARVD), mitochondrial disease, Fabry's disease of the heart and prolonged Q-T interval syndrome. The total number of patients was estimated at 17,700 for DCM, 21,900 for HCM, 300 for RCM, 520 for ARVD, 640 for mitochondrial disease, 150 for Fabry's disease of the heart, and 1,000 for prolonged Q-T interval syndrome. The prevalence of both DCM and HCM was higher in men than women: the male-to-female ratios were 2.6 and 2.3 for DCM and HCM, respectively. Detailed data on patients with DCM or HCM were collected by a follow-up survey. In 1 year more patients with DCM (5.6\%) died than with $\mathrm{HCM}(2.8 \%)$ : congestive heart failure (CHF) and arrhythmias were the leading causes of death for DCM and HCM, respectively. Angiotensin converting enzyme inhibitors (64.6\%) and $\beta$-adrenergic blockers (40.9\%) are commonly used to treat the CHF complicating DCM and may be associated with the clinical improvement in a significant number of DCM patients. Thus, the nationwide surveys of Japanese patients have yielded important current epidemiological and clinical information on the characteristics of cardiomyopathies in Japan. (Circ J 2002; 66: 323-336)
\end{abstract}

Key Words: Cardiomyopathy; Epidemiology; Prevalence

C ongestive heart failure (CHF), often the result of cardiomyopathies, is a major health concern in developed countries! Cardiomyopathy may present as idiopathic dilated (DCM), hypertrophic (HCM) or restrictive (RCM), arrhythmogenic right ventricular dysplasia (ARVD), and several other distinct disorders of the heart muscle? DCM, HCM and RCM are heterogeneous myocardial disorders with multifactorial etiologies, including genetic anomalies and acquired immune pathogenetic factors, such as viral infections s $^{3-5}$ DCM is relatively common and can cause severe CHF. Together with ischemic heart disease, it is the main antecedent of heart transplantation in Western countries, where epidemiologic studies performed a decade ago measured 5-year survival rates as low as $30-40 \%$ after initial diagnosis, 6 , In contrast, few large-scale studies have been conducted to examine the prevalence, prognosis and management patterns of cardio-

(Received August 3, 2001; revised manuscript received December 28, 2001; accepted January 18, 2002)

Department of Cardiovascular Medicine, Kyoto University Graduate School of Medicine, Kyoto, *Department of Public Health, Kanazawa Medical University, Ishikawa, **Department of Preventive Medicine/ Biostatistics and Medical Decision Making, Nagoya University Graduate School of Medicine, Nagoya and Department of Epidemiology and Environmental Health, Juntendo University School of Medicine, Tokyo, Japan

$\$$ Co-research workers are listed in Appendix.

Mailing address: Akira Matsumori, MD, PhD, Department of Cardiovascular Medicine, Kyoto University Graduate School of Medicine, 54 Kawahara-cho, Shogoin, Sakyo-ku, Kyoto 606-8397, Japan. E-mail: amat@kuhp.kyoto-u.ac.jp myopathies in Asian populations. In addition, recent advances in the pharmacological treatment of CHF, such as the widespread use of angiotensin-converting enzyme (ACE) inhibitors and $\beta$-adrenergic receptor blockers, have improved the prognosis of DCM over the past decade. Because of the recent reintroduction of cardiac transplantation in Japan, it has become particularly important to precisely assess the prognosis of patients with cardiomyopathies? ${ }^{8} 9$

This study, based on nationwide surveys, aimed to estimate the current prevalence of the cardiomyopathies in general, and to develop detailed clinical and epidemiologic profiles of patients suffering from 3 representative myopathic disorders: DCM, HCM and RCM. Epidemiological analyses of other cardiomyopathies, such as ARVD, mitochondrial disease, Fabry's disease of the heart and prolonged Q-T interval syndrome were also carried out during this study.

\section{Methods}

Nationwide surveys on DCM, HCM and RCM as well as another series of surveys on other cardiomyopathies, including ARVD, mitochondrial disease, Fabry's disease of the heart and prolonged Q-T interval syndrome, were designed to reveal the prevalence and clinical characteristics of these diseases in Japan! ${ }^{10,11}$ The diseases were classified according to the criteria established by the Research Committee on Idiopathic Cardiomyopathy, Japan,$^{12}$ which emulates the report of the 1980 World Health Organization/International 
Table 1 Age and Sex Distributions of the Cardiomyopathies

\begin{tabular}{|c|c|c|c|c|c|c|c|c|c|}
\hline \multirow{2}{*}{ Age group } & \multicolumn{3}{|c|}{$D C M$} & \multicolumn{3}{|c|}{$H C M$} & \multicolumn{3}{|c|}{$R C M$} \\
\hline & Male & Female & Total & Male & Female & Total & Male & Female & Total \\
\hline $0-9$ & 12 & 16 & 28 & 11 & 14 & 25 & 1 & 1 & 2 \\
\hline $10-19$ & 12 & 10 & 22 & 55 & 31 & 86 & 2 & 2 & 4 \\
\hline $20-29$ & 38 & 16 & 54 & 39 & 31 & 70 & 3 & 0 & 3 \\
\hline $30-39$ & 100 & 13 & 113 & 61 & 20 & 81 & 1 & 0 & 1 \\
\hline $40-49$ & 204 & 55 & 259 & 152 & 50 & 202 & 0 & 0 & 0 \\
\hline $50-59$ & 360 & 85 & 445 & 348 & 101 & 449 & 1 & 1 & 2 \\
\hline $60-69$ & 417 & 178 & 595 & 506 & 184 & 690 & 5 & 3 & 8 \\
\hline $70-79$ & 201 & 128 & 329 & 267 & 163 & 430 & 1 & 4 & 5 \\
\hline$\geq 80$ & 56 & 31 & 87 & 51 & 50 & 101 & 0 & 1 & 1 \\
\hline Total & 1,400 & 532 & 1,932 & 1,490 & 644 & 2,134 & 14 & 12 & 26 \\
\hline
\end{tabular}

DCM, dilated cardiomyopathy; HCM, hypertrophic cardiomyopathy; RCM, restrictive cardiomyopathy; ARVD, arrhythmogenic right ventricular dysplasia. Patients without data for the assessment ("unknown cases") were excluded from the total subject numbers in each category.

Society and Federation of Cardiology task force on the definition and classification of cardiomyopathies $!^{3}$

The hospitals included in each survey were randomly selected by stratified sampling of all departments of internal medicine, cardiovascular medicine and pediatrics throughout Japan, identified in a directory of names, department addresses, and number of hospital beds obtained from the Ministry of Health and Welfare in Japan. Sampling rates of approximately 5, 10, 20, 40, 80 and 100\% were assigned for the stratum of general hospitals with 20-99, 100-199, 200-299, 300-399, 400-499 and 500 or greater number of beds, respectively.

The questionnaire for the first survey on DCM, HCM and RCM was directly mailed to 2,414 departments $(1,496$ departments of cardiovascular/internal medicine and 918 departments of pediatrics) in January 1999. Of those, 1,409 $(58.4 \%)$ responded, reporting a total of 13,675 patients with these cardiomyopathies! ${ }^{0}$ The questionnaire investigated the number of patients with DCM, HCM or RCM visiting and/or receiving treatment as either inpatients or outpatients in the specific departments in 1998. In the second questionnaire sent to the departments reporting patients in the first survey, detailed data were collected from a total of 4,348 patients $(31.8 \%$ of the reported patients in the first survey). The second questionnaire requested detailed clinico-epidemiological information regarding each patient identified by the first survey, including age and sex, symptoms attributable to CHF and arrhythmias, objective physical findings, data from electrocardiogram (ECG), chest X-ray, echocardiography and blood tests as well as prescription, prognosis and clinical evolution. Patients who were not examined or whose data were not available was defined as the 'unknown' population for each parameter. The percentage of patients in a subgroup was calculated from the ratio of the patients in the group to all subjects with available data for each parameter.

The surveys on ARVD, mitochondrial disease, Fabry's disease of the heart and prolonged Q-T interval syndrome were conducted as part of nationwide surveys on 46 intractable diseases, independent of the surveys on DCM, $\mathrm{HCM}$ and RCM 10 The questionnaire, which requested the numbers of patients with these diseases was mailed to 2,917 departments (1,461 departments of cardiovascular/internal medicine, 939 departments of pediatrics and 517 departments of cardiovascular surgery) in January 1999 and of these, $1,928(66.1 \%)$ responded. A further questionnaire regarding clinico-epidemiological information of ARVD, mitochondrial disease, Fabry's disease of the heart and prolonged Q-T interval syndrome was sent to 117 selected hospitals and of these, $76(65.0 \%)$ hospitals for ARVD, 73 $(62.4 \%)$ for mitochondrial disease, $74(63.2 \%)$ for Fabry's disease of the heart and $75(64.1 \%)$ for prolonged Q-T interval syndrome responded. Selected sections of the questionnaire were used to survey patients with these relatively uncommon diseases.

The numbers of patients with DCM, HCM or RCM and the diseases' prevalence were estimated from the results of the follow-up survey. Patients who died prior to 1998 or those visiting a hospital for the first time after 1999 were excluded from this study as inappropriate cases, as were patients whose data were reported from more than one department (duplicate cases). The estimated total number of patients with each cardiomyopathy in Japan was then extrapolated by the formulae contained in the manual prepared by the Epidemiology of Intractable Diseases Research Committee of the Ministry of Health and Welfare of Japan! $10,11,14$ Briefly, it was assumed that the mean prevalence of the patients among the departments responding to the survey was equal to that among departments not responding. Formulas to estimate the total number of patients

Table 2 Family History

\begin{tabular}{lccr}
\hline \hline & DCM & $H C M$ & RCM \\
\hline Family history & & & \\
$(+)$ & $100(6.2 \%)$ & $300(17.6 \%)$ & $6(28.6 \%)$ \\
$(-)$ & $1,520(93.8 \%)$ & $1,404(82.4 \%)$ & $15(71.4 \%)$ \\
Sub total & $1,620(100.0 \%)$ & $1,704(100.0 \%)$ & $21(100.0 \%)$ \\
Unknown cases & 312 & 430 & 5 \\
Total & 1,932 & 2,134 & 26 \\
\hline
\end{tabular}




\begin{tabular}{|c|c|c|c|c|c|c|c|c|c|c|c|}
\hline \multicolumn{3}{|c|}{$A R V D$} & \multicolumn{3}{|c|}{ Mitochondrial disease } & \multicolumn{3}{|c|}{$\begin{array}{c}\text { Fabry's disease } \\
\text { of the heart }\end{array}$} & \multicolumn{3}{|c|}{$\begin{array}{c}\text { Prolonged } Q-T \\
\text { interval syndrome }\end{array}$} \\
\hline Male & Female & Total & Male & Female & Total & Male & Female & Total & Male & Female & Total \\
\hline 0 & 0 & 0 & 0 & 0 & 0 & 0 & 0 & 0 & 0 & 0 & 0 \\
\hline 4 & 1 & 5 & 1 & 0 & 1 & 0 & 0 & 0 & 4 & 6 & 10 \\
\hline 3 & 2 & 5 & 4 & 1 & 5 & 1 & 0 & 1 & 9 & 14 & 23 \\
\hline 7 & 2 & 9 & 1 & 1 & 2 & 1 & 0 & 1 & 2 & 10 & 12 \\
\hline 9 & 8 & 17 & 6 & 4 & 10 & 1 & 0 & 1 & 0 & 5 & 5 \\
\hline 10 & 4 & 14 & 3 & 3 & 6 & 2 & 2 & 4 & 1 & 8 & 9 \\
\hline 5 & 4 & 9 & 1 & 0 & 1 & 6 & 2 & 8 & 1 & 3 & 4 \\
\hline 3 & 1 & 4 & 0 & 0 & 0 & 2 & 0 & 2 & 0 & 5 & 5 \\
\hline 0 & 0 & 0 & 0 & 0 & 0 & 0 & 0 & 0 & 0 & 2 & 2 \\
\hline 41 & 22 & 63 & 16 & 9 & 25 & 13 & 4 & 17 & 17 & 53 & 70 \\
\hline
\end{tabular}

and the $95 \%$ confidence interval are described in detail elsewhere! $10,11,14$ The calculated total number of patients was corrected by multiplying the number by $(1-$ the proportions of duplicate cases and inappropriate cases among the patients reported in the follow-up survey). The population of Japan in 1998 was used to estimate the crude prevalence of each disease per 100,000 population and crude incidence was computed by multiplying the estimated prevalence of patients per 100,000 by the proportion of patients newly diagnosed in 1998; the proportion was obtained from the follow-up survey. Age- and sex-specific prevalence rates were also estimated; the estimation was based on the age distribution of patients by sex obtained from the follow-up survey.

To estimate the numbers of patients with ARVD, mitochondrial disease, Fabry's disease of the heart or prolonged Q-T interval syndrome and the crude prevalence of each disease, we used the results of the survey on the numbers of patients with these diseases.

The data were analyzed by $\mathrm{X}^{2}$ test for comparison between DCM and HCM.

\section{Results}

Number and Distribution by Age and Sex of the Reported Patients With DCM, HCM, RCM and Other Cardiomyopathies

Detailed data from 4,348 patients with DCM, HCM or RCM were collected by the follow-up survey. Unconfirmed or duplicated cases, and cases with undocumented sex or age (256 patients) were excluded. Ultimately, data from 4,092 patients from the second survey were analyzed for DCM, HCM and RCM; 1,932 patients with DCM, 2,134 with HCM, 26 with RCM.

From the results of the clinico-epidemiological survey on ARVD, mitochondrial disease, Fabry's disease of the heart and prolonged Q-T interval syndrome, detailed data on 63 patients with ARVD, 25 with mitochondrial disease, 17 with Fabry's disease of the heart, and 70 with prolonged Q-T interval syndrome were collected.

The total number $(95 \% \mathrm{CI})$ of patients was estimated at $17,700(16,500-18,800)$ for DCM, 21,900 (20,600-23,200) for HCM, 300 (250-350) for RCM, 520 (360-680) for

Table 3 Time From Onset to First Consultation and Follow-up Period

\begin{tabular}{|c|c|c|c|}
\hline & $D C M$ & $H C M$ & $R C M$ \\
\hline \multicolumn{4}{|c|}{ Time to first consult (years) } \\
\hline$<1$ & $763(70.7 \%)$ & $363(52.0 \%)$ & $8(57.1 \%)$ \\
\hline $1-2$ & $79(7.3 \%)$ & $64(9.2 \%)$ & $1(7.1 \%)$ \\
\hline $2-3$ & $45(4.2 \%)$ & $46(\quad 6.6 \%)$ & - \\
\hline $3-4$ & $53(4.9 \%)$ & $36(5.2 \%)$ & $1(7.1 \%)$ \\
\hline $4-5$ & $22(2.0 \%)$ & $28(4.0 \%)$ & - \\
\hline $5-10$ & $78(7.2 \%)$ & $85(12.2 \%)$ & $1(7.1 \%)$ \\
\hline$\geq 10$ & $39(3.6 \%)$ & $76(10.9 \%)$ & $3(21.4 \%)$ \\
\hline Sub total & $1,079(100.0 \%)$ & $698(100.0 \%)$ & $14(100.0 \%)$ \\
\hline Unknown cases & 853 & 1,436 & 12 \\
\hline Total & 1,932 & 2,134 & 26 \\
\hline \multicolumn{4}{|l|}{ Follow-up (years) } \\
\hline$<1$ & $316(19.7 \%)$ & $355(20.4 \%)$ & $2(8.3 \%)$ \\
\hline $1-2$ & $270(16.8 \%)$ & $181(10.4 \%)$ & $5(20.8 \%)$ \\
\hline $2-3$ & $215(13.4 \%)$ & $146(8.4 \%)$ & $5(20.8 \%)$ \\
\hline $3-4$ & $154(9.6 \%)$ & $133(7.6 \%)$ & $3(12.5 \%)$ \\
\hline $4-5$ & $123(7.7 \%)$ & $115(6.6 \%)$ & $2(8.3 \%)$ \\
\hline $5-10$ & $357(22.3 \%)$ & $423(24.3 \%)$ & - \\
\hline$\geq 10$ & $169(10.5 \%)$ & $391(22.4 \%)$ & $7(29.2 \%)$ \\
\hline Sub total & $1,604(100.0 \%)$ & $1,744(100.0 \%)$ & $24(100.0 \%)$ \\
\hline Unknown cases & 328 & 390 & 2 \\
\hline Total & 1,932 & 2,134 & 26 \\
\hline
\end{tabular}


Table 4 Clinical Outcome

\begin{tabular}{lccc}
\hline \hline & DCM & HCM & RCM \\
\hline Healed & $1(0.1 \%)$ & - & - \\
Improved & $902(48.3 \%)$ & $368(18.5 \%)$ & $5(19.2 \%)$ \\
No change & $748(40 \%)$ & $1,427(82.3 \%)$ & $13(50.0 \%)$ \\
Worsen & $113(6.0 \%)$ & $126(6.4 \%)$ & $5(19.2 \%)$ \\
Death & $104(5.6 \%)$ & $53(2.8 \%)$ & $3(11.5 \%)$ \\
Sub total & $1,868(100.0 \%)$ & $1,974(100.0 \%)$ & $26(100.0 \%)$ \\
Unknown cases & 64 & 160 & 0 \\
Total & 1,932 & 2,134 & 26 \\
\hline
\end{tabular}

Table 5 Period From First Medical Consult to Death and Causes of Death

\begin{tabular}{lccc}
\hline \hline & $D C M$ & $H C M$ & $R C M$ \\
\hline Time to first consult (years) & $21(21.2 \%)$ & $13(29.5 \%)$ & - \\
$<1$ & $19(19.2 \%)$ & $2(4.5 \%)$ & $1(33.3 \%)$ \\
$1-2$ & $11(11.1 \%)$ & $3(6.8 \%)$ & - \\
$2-3$ & $5(5.1 \%)$ & $4(9.1 \%)$ & $1(33.3 \%)$ \\
$3-4$ & $3(3.0 \%)$ & $2(4.5 \%)$ & $1(33.3 \%)$ \\
$4-5$ & $29(29.3 \%)$ & $9(20.5 \%)$ & - \\
$5-10$ & $11(11.1 \%)$ & $11(25.0 \%)$ & - \\
$\geq 10$ & $99(100.0 \%)$ & $44(100.0 \%)$ & $3(100.0 \%)$ \\
Sub total & 5 & 9 & 3 \\
Unknown cases & 104 & 53 & $3(100.0 \%)$ \\
Total & & $10(21.3 \%)$ & - \\
\hline Cause of death & $49(49.5 \%)$ & $15(31.9 \%)$ & - \\
Congestive heart failure & $20(20.2 \%)$ & $1(2.1 \%)$ & - \\
Arrhythmia & $8(8.1 \%)$ & $21(44.7 \%)$ & $3(100.0 \%)$ \\
Other cardiac death & $22(22.2 \%)$ & $47(100.0 \%)$ & - \\
Non-cardiac death & $99(100.0 \%)$ & 6 & 3 \\
Sub total & 5 & 53 & \\
Unknown cases & 104 & & \\
Total & & & \\
\hline
\end{tabular}

Each total number indicates the number of patients who died during 1998.

ARVD, 640 (500-780) for mitochondrial disease, 150 (95-205) for Fabry's disease of the heart, and 1,000 (690$1,320)$ for prolonged Q-T interval syndrome. The age distribution by sex of the patients with the cardiomyopathies is shown in Table 1.

The male/female ratio for DCM was 2.6, for patients aged between 1 and 93 years, 2.3 for HCM, for patients aged between 1 and 100 years, and 1.2 for RCM in patients aged between 1 and 81 years old. The majority (45 of 70) of the patients with prolonged Q-T interval syndrome were younger than 40 years, whereas more than $60 \%$ of the patients with other cardiomyopathies were aged 40 years or older.

The estimated prevalences of DCM, HCM and RCM as well as those of other myocardial diseases have been reported elsewhere ${ }^{10,11}$

\section{Analysis of DCM vs HCM}

Because the numbers of patients with RCM, ARVD and the other less common forms of myocardial disease identified in this survey were relatively small, most comparative analyses were limited to patients with DCM or HCM.

The percentage of concordant family histories was $6.2 \%$ in patients with DCM vs $17.6 \%$ in patients with HCM (Table 2). The time interval from the onset of symptoms and to the first medical examination was less than 1 year in more than $50 \%$ of patients with a diagnosis of DCM, HCM or RCM, and although the follow up was less than 5 years in the majority of the patients, $10.5 \%$ of DCM and $22.4 \%$ of HCM patients were followed for 10 years or more (Table 3 ). Significantly more patients with DCM died during 1 year $(5.6 \%)$ than with $\mathrm{HCM}\left(2.8 \%, \mathrm{X}^{2}=26.9, \mathrm{p}<0.0001\right)$, and treatment-related clinical improvement was reported in more cases of DCM (48.3\%) than HCM (18.5\%). More patients with HCM $(82.3 \%)$ reported neither improvement nor worsening of their symptoms (Table 4).

With respect to the period from the first medical consult to death, the percentages of patients who survived for more than 5 years after the first medical consult were $40.4 \%$ for DCM and $45.5 \%$ for HCM (Table 5). Among all fatal outcomes, the percentage of deaths occurring during the 1st year after the first medical consult was $21.2 \%$ for DCM and $29.5 \%$ in patients with HCM (Table 5). CHF was the leading cause of death in patients with DCM (49.5\%), followed by arrhythmias $(20.2 \%)$, whereas more patients with HCM died of arrhythmias (31.9\%) than of CHF (21.3\%).

Histories of hypertension and diabetes mellitus were elicited in $20.8 \%$ and $13.4 \%$ of DCM patients, respectively, vs $31.0 \%$ and $9.1 \%$ of HCM patients, respectively (Table 6 ), and there was no difference between DCM and HCM in the percentage of patients taking insulin therapy (data not shown). According to both the New York Heart Association 
Table 6 Medical History and Social Habits

\begin{tabular}{|c|c|c|c|}
\hline & $D C M$ & $H C M$ & $R C M$ \\
\hline \multicolumn{4}{|l|}{ Hypertension } \\
\hline$(+)$ & $382(20.8 \%)$ & $609(31.0 \%)$ & $1(4.3 \%)$ \\
\hline$(-)$ & $1,451(79.2 \%)$ & $1,356(69.0 \%)$ & $22(95.7 \%)$ \\
\hline Sub total & $1,833(100.0 \%)$ & $1,965(100.0 \%)$ & $23(100.0 \%)$ \\
\hline Unknown cases & 99 & 169 & 3 \\
\hline Total & 1,932 & 2,134 & 26 \\
\hline \multicolumn{4}{|l|}{ Diabetes mellitus } \\
\hline$(+)$ & $250(13.4 \%)$ & $179(9.1 \%)$ & - \\
\hline$(-)$ & $1,615(86.6 \%)$ & $1,791(90.9 \%)$ & $26(100.0 \%)$ \\
\hline Sub total & $1,865(100.0 \%)$ & $1,970(100.0 \%)$ & $26(100.0 \%)$ \\
\hline Unknown cases & 67 & 164 & - \\
\hline Total & 1,932 & 2,134 & 26 \\
\hline \multicolumn{4}{|l|}{ Alcohol } \\
\hline$(+)$ & $605(35.6 \%)$ & $640(36.7 \%)$ & $2(8.3 \%)$ \\
\hline$(-)$ & $1,093(64.4 \%)$ & $1,103(63.3 \%)$ & $22(91.7 \%)$ \\
\hline Sub total & $1,698(100.0 \%)$ & $1,743(100.0 \%)$ & $24(100.0 \%)$ \\
\hline Unknown cases & 234 & 391 & 2 \\
\hline Total & 1,932 & 2,134 & 26 \\
\hline \multicolumn{4}{|l|}{ Smoking } \\
\hline Smoker & $677(39.5 \%)$ & $711(39.4 \%)$ & $7(28.0 \%)$ \\
\hline Non smoker & $1,039(60.5 \%)$ & $1,095(60.6 \%)$ & $18(72.0 \%)$ \\
\hline Sub total & $1,716(100.0 \%)$ & $1,806(100.0 \%)$ & $25(100.0 \%)$ \\
\hline Unknown cases & 216 & 328 & 1 \\
\hline Total & 1,932 & 2,134 & 26 \\
\hline
\end{tabular}

Table 7 Diagnosis of Congestive Heart Failure

\begin{tabular}{lccc}
\hline \hline & DCM & HCM & RCM \\
\hline NYHA functional classification & & & \\
I & $402(22.4 \%)$ & $1,245(66.6 \%)$ & $8(34.8 \%)$ \\
II & $719(40.0 \%)$ & $527(28.2 \%)$ & $6(26.1 \%)$ \\
III & $492(27.4 \%)$ & $80(4.3 \%)$ & $8(34.8 \%)$ \\
IV & $185(10.3 \%)$ & $17(0.9 \%)$ & $1(4.3 \%)$ \\
Sub total & $1,798(100.0 \%)$ & $1,869(100.0 \%)$ & $23(100.0 \%)$ \\
Unknown cases & 134 & 265 & 3 \\
Total & 1,932 & 2,134 & 26 \\
\hline Specific activity scale (Mets) & & & \\
$\geq 7.0$ & $44(18.0 \%)$ & $74(46.0 \%)$ & - \\
3.7-6.9 & $113(46.1 \%)$ & $78(48.4 \%)$ & - \\
S3.6 & $88(35.9 \%)$ & $9(5.6 \%)$ & $3(100.0 \%)$ \\
Sub total & $245(100.0 \%)$ & $161(100.0 \%)$ & 23 \\
Unknown cases & 1,687 & 1,973 & 26 \\
Total & 1,932 & 2,134 & \\
\hline
\end{tabular}

NYHA, New York Heart Association.

Table 8 Chest X-ray Findings

\begin{tabular}{lccc}
\hline \hline & DCM & HCM & RCM \\
\hline CTR $(\%)$ & & & \\
$<50$ & $255(14.5 \%)$ & $499(28.3 \%)$ & $3(13.0 \%)$ \\
$\geq 50$ & $1,504(85.5 \%)$ & $1,267(71.7 \%)$ & $20(87.0 \%)$ \\
Sub total & $1,759(100.0 \%)$ & $1,766(100.0 \%)$ & $23(100.0 \%)$ \\
Unknown cases & 173 & 368 & 3 \\
Total & 1,932 & 2,134 & 26 \\
\hline
\end{tabular}

CTR, cardiothoracic ratio. 
Table 9 Electrocardiography

\begin{tabular}{|c|c|c|c|}
\hline & $D C M$ & $H C M$ & $R C M$ \\
\hline \multicolumn{4}{|l|}{ Standard 12-lead ECG } \\
\hline \multicolumn{4}{|l|}{ Basic rhythm } \\
\hline Sinus rhythm & $1,313(70.8 \%)$ & $1,804(90.5 \%)$ & $17(68.0 \%)$ \\
\hline Atrial fibrillation & $476(25.7 \%)$ & $150(7.5 \%)$ & $5(20.0 \%)$ \\
\hline Atrial flutter & $27(1.5 \%)$ & $16(0.8 \%)$ & $1(4.0 \%)$ \\
\hline Artificial pacemaker rhythm & $32(1.7 \%)$ & $13(0.7 \%)$ & $2(8.0 \%)$ \\
\hline Other & $7(0.4 \%)$ & $11(0.6 \%)$ & - \\
\hline Total & $1,855(100.0 \%)$ & 1,994 (100.0\%) & $25(100.0 \%)$ \\
\hline \multicolumn{4}{|l|}{ Left ventricular hypertrophy } \\
\hline$(+)$ & $685(38.9 \%)$ & $1,367(69.1 \%)$ & $9(45.0 \%)$ \\
\hline$(-)$ & $1,076(61.1 \%)$ & $610(30.9 \%)$ & $11(55.0 \%)$ \\
\hline Total & $1,761(100.0 \%)$ & $1,977(100.0 \%)$ & $20(100.0 \%)$ \\
\hline \multicolumn{4}{|l|}{ Left bundle branch block } \\
\hline$(+)$ & $240(14.5 \%)$ & $60(3.4 \%)$ & $20(90.9 \%)$ \\
\hline$(-)$ & $1,413(85.5 \%)$ & $1,727(96.6 \%)$ & $2(9.1 \%)$ \\
\hline Total & $1,653(100.0 \%)$ & $1,787(100.0 \%)$ & $22(100.0 \%)$ \\
\hline \multicolumn{4}{|l|}{ Holter 24-h ECG } \\
\hline \multicolumn{4}{|l|}{$R$ on $T$} \\
\hline$(+)$ & $24(2.3 \%)$ & $9(0.8 \%)$ & - \\
\hline$(-)$ & $1,009(97.7 \%)$ & $1,086(99.2 \%)$ & $14(100.0 \%)$ \\
\hline Total & $1,033(100.0 \%)$ & $1,095(100.0 \%)$ & $14(100.0 \%)$ \\
\hline \multicolumn{4}{|l|}{ Non-sustained VT } \\
\hline$(+)$ & $359(31.8 \%)$ & $211(18.7 \%)$ & $2(12.5 \%)$ \\
\hline$(-)$ & $770(68.2 \%)$ & $918(81.3 \%)$ & $14(87.5 \%)$ \\
\hline Total & $1,129(100.0 \%)$ & $1,129(100.0 \%)$ & $16(100.0 \%)$ \\
\hline \multicolumn{4}{|l|}{ Sustained VT } \\
\hline$(+)$ & $14(1.3 \%)$ & $7(0.6 \%)$ & - \\
\hline$(-)$ & $1,079(98.7 \%)$ & $1,111(99.4 \%)$ & $16(100.0 \%)$ \\
\hline Total & $1,093(100.0 \%)$ & $1,118(100.0 \%)$ & $16(100.0 \%)$ \\
\hline \multicolumn{4}{|l|}{ Paroxysmal atrial fibrillation } \\
\hline$(+)$ & $71(7.1 \%)$ & $89(8.2 \%)$ & $1(7.1 \%)$ \\
\hline$(-)$ & 931 (92.9\%) & $991(91.8 \%)$ & $13(92.9 \%)$ \\
\hline Total & $1,002(100.0 \%)$ & $1,080(100.0 \%)$ & $14(100.0 \%)$ \\
\hline
\end{tabular}

Patients without data for the assessment ("unknown cases") were excluded from the total subject numbers in each category.

(NYHA) functional classification and the Specific Activity Scale, which estimates the patient's exercise capacity, a higher proportion of DCM than HCM patients suffered from severe CHF (Table 7). On the other hand, cardiomegaly on chest roentgenogram was common in both DCM (85.5\%) and HCM (71.7\%) patients (Table 8).

\section{Electrocardiography (Table 9)}

A higher prevalence of permanent atrial fibrillation was found among patients with DCM $(25.7 \%)$ than with HCM $(7.5 \%)$, whereas paroxysmal atrial fibrillation was found in $7.1 \%$ of DCM and in $8.2 \%$ of $\mathrm{HCM}$ patients. A paced rhythm was recorded in $1.7 \%$ of DCM vs $0.7 \%$ of HCM patients. Left ventricular hypertrophy ( $\mathrm{LVH})$ by voltage criteria was found on the ECG in $38.9 \%$ of DCM vs $69.1 \%$ of HCM patients, and left bundle branch block in $14.5 \%$ DCM vs $3.4 \%$ of HCM patients. On 24-h ambulatory ECG, nonsustained ventricular tachycardia was recorded in $31.8 \%$ of patients with DCM vs $18.7 \%$ of HCM patients.

\section{Echocardiography (Table 10)}

In DCM patients, LV dilatation was present in $92.9 \%$, a decreased $(<50 \%) \mathrm{LV}$ ejection fraction (LVEF) in $85.0 \%$, and $13.9 \%$ of the patients had an LVEF $\leq 20 \%$. Mitral regurgitation was observed in $81.0 \%$ of patients, of grade $\geq \mathrm{II} / \mathrm{IV}$ in $44.9 \%$. Tricuspid regurgitation was present in $62.6 \%$ of patients, of grade $\geq \mathrm{II} / \mathrm{IV}$ in $23.6 \%$.

In HCM patients, an increased thickness of the interventricular septum was observed in $90.3 \%$, and asymmetric septal hypertrophy and apical hypertrophy in $54.6 \%$ and
$42.7 \%$ of patients, respectively. Systolic anterior motion of the mitral anterior leaflet was present in $25.3 \%$, and mitral and tricuspid regurgitation were seen in $60.5 \%$ and $39.7 \%$, respectively.

\section{Cardiac Catheterization (Tables 11-13)}

In DCM, LV end-diastolic pressure was increased in $44.0 \%$, cardiac output was depressed in $21.8 \%$, and a LVEF $\leq 20 \%$ was measured in $13.5 \%$ of patients. In HCM, LV enddiastolic pressure was increased in $60.1 \%$ and an intraventricular pressure gradient was present in $21.2 \%$ of patients.

The prevalence and severity of myocardial fibrosis on histological examination of endomyocardial biopsy specimens were comparable in DCM and HCM. Cellular infiltration was more common in DCM, whereas cardiac myocyte hypertrophy and disarray were more abundant in HCM.

\section{Radioisotope Imaging (Table 14) and Exercise Tests (Table 15)}

Equilibrium radionuclide angiocardiography showed a LVEF $<50 \%$ in $94.0 \%$ of patients with DCM vs $18.9 \%$ of patients with HCM. A LVEF $\leq 20 \%$ was observed in $22.2 \%$ of DCM vs $1.4 \%$ of HCM patients. A decreased myocardial thallium-201 $\left({ }^{201} \mathrm{Tl}\right)$ uptake was common in both DCM $(76.1 \%)$ and $\mathrm{HCM}(50.3 \%)$.

Treadmill exercise capacity was $<7$ Mets in $51.4 \%$ of DCM patients vs $28.0 \%$ of HCM patients. A peak respiratory oxygen uptake $<24.5 \mathrm{ml} \cdot \mathrm{kg}^{-1} \cdot \mathrm{min}^{-1}$ was measured in $79.6 \%$ of DCM vs $60.0 \%$ of HCM patients. 
Table 10 Echocardiography

\begin{tabular}{|c|c|c|c|}
\hline & $D C M$ & $H C M$ & $R C M$ \\
\hline \multicolumn{4}{|c|}{ LVEDd (mm) } \\
\hline$\geq 50$ & $1,708(92.9 \%)$ & $502(25.8 \%)$ & $5(21.7 \%)$ \\
\hline$<50$ & $130(7.1 \%)$ & $1,446(74.2 \%)$ & $18(78.3 \%)$ \\
\hline Total & $1,838(100.0 \%)$ & $1,948(100.0 \%)$ & $23(100.0 \%)$ \\
\hline \multicolumn{4}{|c|}{ LVEDd index (LVEDd/BSA) $\left(\mathrm{mm} / \mathrm{m}^{2}\right)$} \\
\hline$\geq 32$ & $1,274(85.3 \%)$ & $277(17.0 \%)$ & $1(5.3 \%)$ \\
\hline$<32$ & $220(14.7 \%)$ & $1,355(83.0 \%)$ & $18(94.7 \%)$ \\
\hline Total & $1,494(100.0 \%)$ & $1,632(100.0 \%)$ & $19(100.0 \%)$ \\
\hline \multicolumn{4}{|c|}{ LV ejection fraction (\%) } \\
\hline$\geq 50$ & $218(15.0 \%)$ & $1,410(93.8 \%)$ & $1(4.8 \%)$ \\
\hline $36-49$ & $442(30.4 \%)$ & $61(4.1 \%)$ & $1(4.8 \%)$ \\
\hline $21-35$ & $593(40.7 \%)$ & $26(1.7 \%)$ & $5(23.8 \%)$ \\
\hline$\leq 20$ & $203(13.9 \%)$ & $7(0.5 \%)$ & $14(66.7 \%)$ \\
\hline Total & $1,456(100.0 \%)$ & $1,504(100.0 \%)$ & $21(100.0 \%)$ \\
\hline \multicolumn{4}{|c|}{$\operatorname{IVSTh}(\mathrm{mm})$} \\
\hline$\geq 11$ & $456(26.3 \%)$ & $1,778(90.3 \%)$ & $14(60.9 \%)$ \\
\hline$<11$ & $1,277(73.7 \%)$ & $191(9.7 \%)$ & $9(39.1 \%)$ \\
\hline Total & $1,733(100.0 \%)$ & $1,969(100.0 \%)$ & $23(100.0 \%)$ \\
\hline \multicolumn{4}{|c|}{ Asymmetric septal hypertrophy } \\
\hline$(+)$ & $13(0.8 \%)$ & $1,025(54.6 \%)$ & $4(19.0 \%)$ \\
\hline$(-)$ & $1,699(99.2 \%)$ & $854(45.4 \%)$ & $17(81.0 \%)$ \\
\hline Total & $1,712(100.0 \%)$ & $1,879(100.0 \%)$ & $21(100.0 \%)$ \\
\hline \multicolumn{4}{|c|}{ Apical hypertrophy } \\
\hline$(+)$ & $4(0.3 \%)$ & $739(42.7 \%)$ & $3(15.0 \%)$ \\
\hline$(-)$ & $1,586(99.7 \%)$ & $993(57.3 \%)$ & $17(85.0 \%)$ \\
\hline Total & $1,590(100.0 \%)$ & $1,732(100.0 \%)$ & $20(100.0 \%)$ \\
\hline \multicolumn{4}{|c|}{ Systolic anterior motion } \\
\hline$(+)$ & $3(0.2 \%)$ & $459(25.3 \%)$ & $1(4.5 \%)$ \\
\hline$(-)$ & $1,705(99.8 \%)$ & $1,357(74.7 \%)$ & $21(95.5 \%)$ \\
\hline Total & $1,708(100.0 \%)$ & $1,816(100.0 \%)$ & $22(100.0 \%)$ \\
\hline \multicolumn{4}{|c|}{$B$ - $B^{\prime}$ step formation } \\
\hline$(+)$ & $153(11.5 \%)$ & $81(6.0 \%)$ & $3(21.4 \%)$ \\
\hline$(-)$ & $1,180(88.5 \%)$ & $1,270(94.0 \%)$ & $11(78.6 \%)$ \\
\hline Total & $1,333(100.0 \%)$ & $1,351(100.0 \%)$ & $14(100.0 \%)$ \\
\hline \multicolumn{4}{|c|}{ Pericardial effusion } \\
\hline$(+)$ & $107(6.4 \%)$ & $63(3.6 \%)$ & $5(23.8 \%)$ \\
\hline$(-)$ & $1,569(93.6 \%)$ & $1,666(96.4 \%)$ & $16(76.2 \%)$ \\
\hline Total & $1,676(100.0 \%)$ & $1,729(100.0 \%)$ & $21(100.0 \%)$ \\
\hline \multicolumn{4}{|c|}{ Mitral regurgitation } \\
\hline- & $281(19.0 \%)$ & $531(39.5 \%)$ & $8(34.8 \%)$ \\
\hline 1 & $534(36.1 \%)$ & $561(41.8 \%)$ & $12(52.2 \%)$ \\
\hline 2 & $423(28.6 \%)$ & $196(14.6 \%)$ & $3(13.0 \%)$ \\
\hline 3 & $197(13.3 \%)$ & $51(3.8 \%)$ & - \\
\hline 4 & $45(3.0 \%)$ & $4(0.3 \%)$ & - \\
\hline Total & $1,480(100.0 \%)$ & $1,343(100.0 \%)$ & $23(100.0 \%)$ \\
\hline \multicolumn{4}{|c|}{ Tricuspid regurgitation } \\
\hline - & $472(37.4 \%)$ & $718(60.3 \%)$ & $8(38.1 \%)$ \\
\hline 1 & $491(38.9 \%)$ & $358(30.1 \%)$ & $10(47.6 \%)$ \\
\hline 2 & $203(16.1 \%)$ & $85(7.1 \%)$ & $2(9.5 \%)$ \\
\hline 3 & $81(6.4 \%)$ & $26(2.2 \%)$ & $1(4.8 \%)$ \\
\hline 4 & $14(1.1 \%)$ & $4(0.3 \%)$ & - \\
\hline Total & $1,261(100.0 \%)$ & $1,191(100.0 \%)$ & $21(100.0 \%)$ \\
\hline \multicolumn{4}{|c|}{ LV inflow $A / E$ ratio } \\
\hline$\geq 1$ & $179(54.9 \%)$ & $285(59.0 \%)$ & $3(37.5 \%)$ \\
\hline$<1$ & $147(45.1 \%)$ & $198(41.0 \%)$ & $5(62.5 \%)$ \\
\hline Total & $326(100.0 \%)$ & $483(100.0 \%)$ & $8(100.0 \%)$ \\
\hline
\end{tabular}

Patients without data for the assessment ("unknown cases") were excluded from the total subject numbers in each category.

\section{Neurohormonal Measurements and Viral Serology (Table 16)}

Plasma levels of atrial natriuretic peptide (ANP) were $\geq 33 \mathrm{pg} / \mathrm{ml}$ in $72.4 \%$ of DCM and in $67.5 \%$ of HCM patients, whereas brain natriuretic peptide (BNP) was $\geq 18.5$ $\mathrm{pg} / \mathrm{ml}$ in $91.4 \%$ of DCM and $90.1 \%$ of HCM patients. A plasma level of norepinephrine $\geq 450 \mathrm{pg} / \mathrm{ml}$ was detected in $31.4 \%$ of DCM and $19.8 \%$ of HCM patients.

In DCM, serology for hepatitis B virus antigen and hepatitis $\mathrm{B}$ antibody was positive in $1.9 \%$ and $8.6 \%$ of patients, respectively, whereas hepatitis $\mathrm{C}$ virus $(\mathrm{HCV})$ antibody and HCV RNA were positive in $6.7 \%$ and $3.5 \%$ of patients, respectively. In HCM, serologic testing for the hepatitis B virus antigen, hepatitis B virus antibody, HCV antibody and HCV RNA was positive in $1.9 \%, 14.6 \%, 9.5 \%$ and $7.2 \%$ of patients, respectively.

Medical Management (Table 17)

ACE inhibitors were administered to $64.6 \%$ and $\beta$ adrenergic blockers to $40.9 \%$ of DCM patients. Carvedilol 
Table 11 Cardiac Catheterization

\begin{tabular}{|c|c|c|c|}
\hline & $D C M$ & $H C M$ & $R C M$ \\
\hline \multicolumn{4}{|c|}{ Systolic aortic pressure $(\mathrm{mmHg})$} \\
\hline$\geq 150$ & $158(16.7 \%)$ & $174(22.8 \%)$ & $1(6.7 \%)$ \\
\hline$<150$ & $788(83.3 \%)$ & $590(77.2 \%)$ & $14(93.3 \%)$ \\
\hline Total & $946(100.0 \%)$ & $764(100.0 \%)$ & $15(100.0 \%)$ \\
\hline \multicolumn{4}{|c|}{ Diastolic aortic pressure $(\mathrm{mmHg})$} \\
\hline$\geq 90$ & $109(11.5 \%)$ & $77(10.2 \%)$ & $1(6.7 \%)$ \\
\hline$<90$ & $835(88.5 \%)$ & $680(89.8 \%)$ & $14(93.3 \%)$ \\
\hline Total & $944(100.0 \%)$ & $757(100.0 \%)$ & $15(100.0 \%)$ \\
\hline \multicolumn{4}{|c|}{$L V$ end-diastolic pressure $(\mathrm{mmH} g)$} \\
\hline$\geq 18$ & $217(21.7 \%)$ & $220(28.4 \%)$ & $12(66.7 \%)$ \\
\hline $12-17$ & $223(22.3 \%)$ & $246(31.7 \%)$ & $4(22.2 \%)$ \\
\hline$\leq 11$ & $560(56.0 \%)$ & $309(39.9 \%)$ & $2(11.1 \%)$ \\
\hline Total & $1,000(100.0 \%)$ & $775(100.0 \%)$ & $18(100.0 \%)$ \\
\hline \multicolumn{4}{|c|}{ Pulmonary capillary wedge pressure $(\mathrm{mmHg})$} \\
\hline$\geq 18$ & $175(16.6 \%)$ & $52(7.6 \%)$ & $8(53.3 \%)$ \\
\hline $12-17$ & $209(19.8 \%)$ & $163(23.7 \%)$ & - \\
\hline$\leq 11$ & $671(63.6 \%)$ & $473(68.8 \%)$ & $7(46.7 \%)$ \\
\hline Total & $1,055(100.0 \%)$ & $688(100.0 \%)$ & $15(100.0 \%)$ \\
\hline \multicolumn{4}{|l|}{ Cardiac index $\left(\mathrm{L} / \mathrm{m}^{2}\right)$} \\
\hline$\geq 2.2$ & $756(78.2 \%)$ & $557(87.6 \%)$ & $9(75.0 \%)$ \\
\hline$<2.2$ & $211(21.8 \%)$ & $79(12.4 \%)$ & $3(25.0 \%)$ \\
\hline Total & $967(100.0 \%)$ & $636(100.0 \%)$ & $12(100.0 \%)$ \\
\hline \multicolumn{4}{|c|}{ Intraventricular pressure gradient } \\
\hline$(+)$ & $2(0.2 \%)$ & $160(21.2 \%)$ & - \\
\hline$(-)$ & $969(99.8 \%)$ & $593(78.8 \%)$ & $15(100.0 \%)$ \\
\hline Total & $971(100.0 \%)$ & $753(100.0 \%)$ & $15(100.0 \%)$ \\
\hline \multicolumn{4}{|c|}{ Site of intraventricular pressure gradient } \\
\hline LV outflow & $2(100.0 \%)$ & $92(70.2 \%)$ & - \\
\hline LV mid-ventricle & - & $36(27.5 \%)$ & - \\
\hline$R V$ & - & $3(2.3 \%)$ & - \\
\hline Total & $2(100.0 \%)$ & $131(100.0 \%)$ & - \\
\hline
\end{tabular}

Patients without data for the assessment ("unknown cases") were excluded from the total subject numbers in each category.

Table 12 Left Ventriculogram and Coronary Arteriogram

\begin{tabular}{lccc}
\hline \hline & $D C M$ & $H C M$ & $R C M$ \\
\hline Ejection fraction (\%) & & & \\
$\geq 50$ & $126(13.4 \%)$ & $602(94.2 \%)$ & $10(83.3 \%)$ \\
$36-49$ & $317(33.6 \%)$ & $24(3.8 \%)$ & $1(8.3 \%)$ \\
$21-35$ & $373(39.6 \%)$ & $12(1.9 \%)$ & $1(8.3 \%)$ \\
$\leq 20$ & $127(13.5 \%)$ & $1(0.2 \%)$ & - \\
Total & $943(100.0 \%)$ & $639(100.0 \%)$ & $12(100.0 \%)$ \\
Mitral regurgitation & $241(40.1 \%)$ & $347(71.8 \%)$ & $7(63.6 \%)$ \\
- & $209(34.8 \%)$ & $98(20.3 \%)$ & $4(36.4 \%)$ \\
1 & $126(21.0 \%)$ & $29(16.0 \%)$ & - \\
2 & $18(3.0 \%)$ & $7(1.6 \%)$ & - \\
3 & $7(1.2 \%)$ & $2(0.4 \%)$ & - \\
4 & $601(100.0 \%)$ & $483(100.0 \%)$ & $11(100.0 \%)$ \\
Total & & & $1(5.9 \%)$ \\
Significant coronary stenosis & $66(5.6 \%)$ & $87(10.0 \%)$ & $16(94.1 \%)$ \\
$(+)$ & $1,103(94.4 \%)$ & $787(90.0 \%)$ & $17(100.0 \%)$ \\
$(-)$ & $1,169(100.0 \%)$ & $874(100.0 \%)$ & \\
Total & & & \\
\end{tabular}

Patients without data for the assessment ("unknown cases") were excluded from the total subject numbers in each category.

was chosen in $18.5 \%$ and metoprolol in $17.0 \%$ of instances. Digitalis was used in $51.5 \%$ of patients. In HCM patients, $\beta$-adrenergic blockers, calcium channel antagonists and ACE inhibitors were used in $39.8 \%, 38.8 \%$ and $21.5 \%$ of patients, respectively. Antiarrhythmic agents other than $\beta$-adrenergic blockers, calcium channel antagonists and cardiac glycosides were used in $24.1 \%$ and $19.7 \%$ of patients with DCM and HCM, respectively. Warfarin anticoagulation was carried out in $26.2 \%$ of patients with DCM, vs $10.8 \%$ of patients with HCM.

\section{Discussion}

The results of the nationwide surveys indicate the prevalence of DCM, HCM and RCM in Japan, and reveal a variety of clinically and epidemiologically important characteristics of these diseases. Furthermore, this study is the first to provide the information on ARVD and other distinct cardiomyopathies including mitochondrial disease, Fabry's disease of the heart, and prolonged Q-T interval syndrome in Japan. 
Table 13 Endomyocardial Biopsy

\begin{tabular}{|c|c|c|c|}
\hline & $D C M$ & $H C M$ & $R C M$ \\
\hline \multicolumn{4}{|l|}{ Fibrosis } \\
\hline- & $96(19.0 \%)$ & $105(31.8 \%)$ & $4(26.7 \%)$ \\
\hline+ & $286(56.5 \%)$ & $156(47.3 \%)$ & $6(40.0 \%)$ \\
\hline++ & $104(20.6 \%)$ & $60(18.2 \%)$ & $3(20.0 \%)$ \\
\hline+++ & $20(4.0 \%)$ & $9(2.7 \%)$ & $2(13.3 \%)$ \\
\hline Total & $506(100.0 \%)$ & $330(100.0 \%)$ & $15(100.0 \%)$ \\
\hline \multicolumn{4}{|c|}{ Mononuclear cell infiltration } \\
\hline- & $358(76.0 \%)$ & $265(84.9 \%)$ & $13(92.9 \%)$ \\
\hline+ & $104(22.1 \%)$ & $41(13.1 \%)$ & $1(7.1 \%)$ \\
\hline++ & $7(1.5 \%)$ & $5(1.6 \%)$ & - \\
\hline+++ & $2(0.4 \%)$ & $1(0.3 \%)$ & - \\
\hline Total & $471(100.0 \%)$ & $312(100.0 \%)$ & $14(100.0 \%)$ \\
\hline \multicolumn{4}{|c|}{ Cardiac myocyte hypertrophy } \\
\hline- & $167(38.3 \%)$ & $57(16.4 \%)$ & $7(50.0 \%)$ \\
\hline+ & $237(54.4 \%)$ & $172(49.6 \%)$ & $3(21.4 \%)$ \\
\hline++ & $24(5.5 \%)$ & $97(28.0 \%)$ & $4(28.6 \%)$ \\
\hline+++ & $8(1.8 \%)$ & $21(6.1 \%)$ & - \\
\hline Total & $436(100.0 \%)$ & $347(100.0 \%)$ & $14(100.0 \%)$ \\
\hline \multicolumn{4}{|c|}{ Myocardial disarray } \\
\hline- & $329(71.8 \%)$ & $124(36.8 \%)$ & $5(38.5 \%)$ \\
\hline+ & $98(21.4 \%)$ & $131(38.9 \%)$ & $4(30.8 \%)$ \\
\hline++ & $28(6.1 \%)$ & $64(19.0 \%)$ & $3(23.1 \%)$ \\
\hline+++ & $3(0.7 \%)$ & $18(5.3 \%)$ & $1(7.7 \%)$ \\
\hline Total & $458(100.0 \%)$ & $337(100.0 \%)$ & $13(100.0 \%)$ \\
\hline
\end{tabular}

Patients without data for the assessment ("unknown cases") were excluded from the total subject numbers in each category.

Table 14 Radioisotope Imaging

\begin{tabular}{lccc}
\hline \hline & DCM & $H C M$ & RCM \\
\hline Equilibrium radionuclide angiocardiography & & & \\
Ejection fraction (\%) & & & \\
$\geq 50$ & $30(6.0 \%)$ & $25(11.1 \%)$ & $2(40.0 \%)$ \\
$36-49$ & $106(21.4 \%)$ & $14(6.3 \%)$ & $2(40.0 \%)$ \\
$21-35$ & $250(50.4 \%)$ & $3(1.4 \%)$ & $1(20.0 \%)$ \\
$\leq 20$ & $110(22.2 \%)$ & $222(100.0 \%)$ & - \\
Sub total & $496(100.0 \%)$ & 1,912 & $5(100.0 \%)$ \\
Unknown cases & 1,436 & 2,134 & 26 \\
Total & 1,932 & & \\
\hline 201 Tl-scintigraphy & & $371(50.3 \%)$ & $6(54.5 \%)$ \\
Decrease in myocardial uptake & $682(76.1 \%)$ & $366(49.7 \%)$ & $5(45.5 \%)$ \\
$(+)$ & $214(23.9 \%)$ & $737(100.0 \%)$ & $11(100.0 \%)$ \\
$(-)$ & $896(100.0 \%)$ & 1,397 & 15 \\
Sub total & 1,036 & 2,134 & 26 \\
Unknown cases & 1,932 & & \\
Total & & & \\
\hline
\end{tabular}

Table 15 Exercise Stress Test

\begin{tabular}{lccc}
\hline \hline & DCM & HCM & RCM \\
\hline VO2max $\left(\mathrm{ml} \cdot \mathrm{kg}^{-1} \cdot \mathrm{min}^{-1}\right)$ & & & \\
$\geq 24.5$ & $20(20.4 \%)$ & $16(40.0 \%)$ & $1(50.0 \%)$ \\
$4-24.5$ & $78(79.6 \%)$ & $24(60.0 \%)$ & $1(50.0 \%)$ \\
$\leq 3$ & - & - & - \\
Total & $98(100.0 \%)$ & $40(100.0 \%)$ & $2(100.0 \%)$ \\
Treadmill exercise test (Mets) & & & \\
$\geq 7.0$ & $144(48.6 \%)$ & $247(72.0 \%)$ & $1(33.3 \%)$ \\
$3.8-6.9$ & $116(39.2 \%)$ & $86(25.1 \%)$ & $1(33.3 \%)$ \\
$\leq 3.7$ & $36(12.2 \%)$ & $10(2.9 \%)$ & $1(33.3 \%)$ \\
Total & $296(100.0 \%)$ & $343(100.0 \%)$ & $3(100.0 \%)$ \\
\hline
\end{tabular}

Patients without data for the assessment ("unknown cases") were excluded from the total subject numbers in each category. 
Table 16 Neurohormonal and Viral Serology

\begin{tabular}{|c|c|c|c|}
\hline & $D C M$ & $H C M$ & $R C M$ \\
\hline \multicolumn{4}{|c|}{$A N P(p g / m l)$} \\
\hline$\geq 33$ & $376(72.4 \%)$ & $160(67.5 \%)$ & $4(80.0 \%)$ \\
\hline$<33$ & $143(27.6 \%)$ & $77(32.5 \%)$ & $1(20.0 \%)$ \\
\hline Total & $519(100.0 \%)$ & $237(100.0 \%)$ & $5(100.0 \%)$ \\
\hline \multicolumn{4}{|c|}{$B N P(p g / m l)$} \\
\hline$\geq 18.5$ & $395(91.4 \%)$ & $173(90.1 \%)$ & $3(100.0 \%)$ \\
\hline$<18.5$ & $37(8.6 \%)$ & $19(9.9 \%)$ & - \\
\hline Total & $432(100.0 \%)$ & $192(100.0 \%)$ & $3(100.0 \%)$ \\
\hline \multicolumn{4}{|c|}{ Norepinephrine $(\mathrm{pg} / \mathrm{ml})$} \\
\hline$\geq 450$ & $95(31.4 \%)$ & $23(19.8 \%)$ & $2(100.0 \%)$ \\
\hline$<450$ & $208(68.6 \%)$ & $93(80.2 \%)$ & - \\
\hline Total & $303(100.0 \%)$ & $116(100.0 \%)$ & $2(100.0 \%)$ \\
\hline \multicolumn{4}{|c|}{ Cardiac troponin $T$} \\
\hline$(+)$ & $3(3.3 \%)$ & $5(9.1 \%)$ & - \\
\hline$(-)$ & $89(96.7 \%)$ & $50(90.9 \%)$ & $2(100.0 \%)$ \\
\hline Total & $92(100.0 \%)$ & $55(100.0 \%)$ & $2(100.0 \%)$ \\
\hline \multicolumn{4}{|c|}{ HBs antigen } \\
\hline$(+)$ & $21(1.9 \%)$ & $17(1.9 \%)$ & - \\
\hline$(-)$ & $1,091(98.1 \%)$ & $882(98.1 \%)$ & $13(100.0 \%)$ \\
\hline Total & $1,112(100.0 \%)$ & $899(100.0 \%)$ & $13(100.0 \%)$ \\
\hline \multicolumn{4}{|c|}{ HBs antibody } \\
\hline$(+)$ & $46(8.6 \%)$ & $62(14.6 \%)$ & - \\
\hline$(-)$ & $487(91.4 \%)$ & $364(85.4 \%)$ & $4(100.0 \%)$ \\
\hline Total & $533(100.0 \%)$ & $426(100.0 \%)$ & $4(100.0 \%)$ \\
\hline \multicolumn{4}{|c|}{ HCV antibody } \\
\hline$(+)$ & $70(6.7 \%)$ & $78(9.5 \%)$ & - \\
\hline$(-)$ & $978(93.3 \%)$ & $743(90.5 \%)$ & $9(100.0 \%)$ \\
\hline Total & $1,048(100.0 \%)$ & $821(100.0 \%)$ & $9(100.0 \%)$ \\
\hline \multicolumn{4}{|c|}{$H C V-R N A$} \\
\hline$(+)$ & $5(3.5 \%)$ & $6(7.2 \%)$ & - \\
\hline$(-)$ & $137(96.5 \%)$ & $77(92.8 \%)$ & - \\
\hline Total & $142(100.0 \%)$ & $83(100.0 \%)$ & - \\
\hline
\end{tabular}

Patients without data for the assessment ("unknown cases") were excluded from the total subject numbers in each category.

\section{Prevalence of DCM}

The estimated patient number in Japan and the prevalence per 100,000 individuals was 17,700, and 14.0, respectively 10 A previous survey, conducted in 1974 by the Idiopathic Cardiomyopathy Research Committee of the Ministry of Health and Welfare of Japan, reported a prevalence of idiopathic cardiomyopathies of 0.56 per 100,000 individuals in the general Japanese population, 15 considerably lower than in recent epidemiologic studies from Western or Middle-Eastern countries ${ }^{16-18}$ However, the prevalence of cardiomyopathies may have been underestimated in that study, because it was conducted before echocardiography became a widespread diagnostic tool and both the standard ECG and chest X-ray are insensitive in detecting cardiomyopathies. In a survey that included echocardiographic data, Kuroda et al found a prevalence of DCM of 15 per 100,000 among individuals undergoing routine health evaluation. 19 Another study in Akita City reported a comparable prevalence of DCM of 12.5 per 100,000 individuals $2^{20}$ Those studies, which surveyed limited territories, suggest that the prevalence of DCM in Japan may be greater than indicated by the 1974 nationwide survey and the higher prevalence detected by the recent surveys can be attributed to superior diagnostic methods, particularly the more frequent use of echocardiography. It is noteworthy that a comparably high prevalence of DCM, ranging between 6.95 and 36.5, has been observed in Western countries: ${ }^{16,21,22}$ Lilienfeld et al studied the prevalence of DCM and HCM in the metropolitan area of St Paul/Minneapolis, MN, USA, in 1979 and again in 1984 and found the prevalence of DCM was 63 per 100,000 men and 35 per 100,000 women in 1974 , vs 125 per 100,000 men and 58 per 100,000 women in $19842^{23}$ Thus, either the absolute prevalence of DCM has recently increased, or the refinements in diagnostic methods are providing more accurate results in Western countries as well as in Japan. In the present study, the prevalence of DCM was 14.0 per 100,000 individuals, which is lower than those recently reported from Western countries, but because this study identified patients with cardiomyopathies from populations who were seeking medical attention, and because DCM may be asymptomatic in its early stages, the prevalence of DCM in Japan may actually be higher.

\section{Prevalence of HCM}

The results indicated that the estimated patient number in Japan and the prevalence per 100,000 individuals was 21,900 and 17.3, respectively ${ }^{10}$ Hada et al ${ }^{24}$ and Kuroda et al ${ }^{19}$ reported a prevalence of HCM in Japan of 170 and 374 per 100,000 individuals, respectively. In Western countries, the prevalence of HCM varies between 19.7 and 1,100 per $100,00017,22,25$ These wide differences in results may be explained by differences in the methods used to conduct the surveys. For instance, if echocardiography is only performed after an abnormal ECG, HCM without electrocardiographic abnormalities will be missed. The prevalence at 17.3 per 100,000 individuals estimated in the present study is lower than previous reports, but an undetermined number of asymptomatic subjects may not have been included in this analysis, which was based on hospital records, thus, perhaps, underestimating the prevalence of HCM. 
Table 17 Medical Treatment

\begin{tabular}{|c|c|c|c|}
\hline & $\overline{D C M}$ & HCM & $R C M$ \\
\hline \multicolumn{4}{|l|}{ Digitalis } \\
\hline$(+)$ & $995(51.5 \%)$ & $138(6.5 \%)$ & $9(34.6 \%)$ \\
\hline$(-)$ & $937(48.5 \%)$ & $1,996(93.5 \%)$ & $17(65.4 \%)$ \\
\hline Total & $1,932(100.0 \%)$ & $2,134(100.0 \%)$ & $26(100.0 \%)$ \\
\hline \multicolumn{4}{|c|}{ Calcium channel antagonists } \\
\hline$(+)$ & $297(15.4 \%)$ & $828(38.8 \%)$ & - \\
\hline$(-)$ & $1,635(84.6 \%)$ & $1,306(61.2 \%)$ & $26(100.0 \%)$ \\
\hline Total & $1,932(100.0 \%)$ & $2,134(100.0 \%)$ & $26(100.0 \%)$ \\
\hline \multicolumn{4}{|l|}{ ACE inhibitors } \\
\hline$(+)$ & $1,248(64.6 \%)$ & $459(21.5 \%)$ & $1(3.8 \%)$ \\
\hline$(-)$ & $684(35.4 \%)$ & $1,675(78.5 \%)$ & $25(96.2 \%)$ \\
\hline Total & $1,932(100.0 \%)$ & $2,134(100.0 \%)$ & $26(100.0 \%)$ \\
\hline \multicolumn{4}{|c|}{$\beta$-adrenergic receptor antagonists } \\
\hline$(+)$ & $790(40.9 \%)$ & $850(39.8 \%)$ & $5(19.2 \%)$ \\
\hline Carvedilol & $358(18.5 \%)$ & $70(3.3 \%)$ & - \\
\hline Metoprolol & $328(17.0 \%)$ & $252(11.8 \%)$ & - \\
\hline Bisoprolol & $32(1.7 \%)$ & $107(5.0 \%)$ & - \\
\hline Others & $72(3.7 \%)$ & $421(19.7 \%)$ & $5(19.2 \%)$ \\
\hline$(-)$ & $1,142(59.1 \%)$ & $1,284(60.2 \%)$ & $21(80.8 \%)$ \\
\hline Total & $1,932(100.0 \%)$ & $2,134(100.0 \%)$ & $26(100.0 \%)$ \\
\hline \multicolumn{4}{|c|}{ Phosphodiesterase inhibitors } \\
\hline$(+)$ & $79(4.1 \%)$ & $7(0.3 \%)$ & $2(7.7 \%)$ \\
\hline$(-)$ & $1,853(95.9 \%)$ & $2,127(99.7 \%)$ & $24(92.3 \%)$ \\
\hline Total & $1,932(100.0 \%)$ & $2,134(100.0 \%)$ & $26(100.0 \%)$ \\
\hline \multicolumn{4}{|c|}{ Anti-arrhythmic agents } \\
\hline$(+)$ & $465(24.1 \%)$ & $421(19.7 \%)$ & $6(23.1 \%)$ \\
\hline Mexiletine & $261(13.5 \%)$ & $102(4.8 \%)$ & $2(7.7 \%)$ \\
\hline Disopyramide & $36(1.9 \%)$ & $120(5.6 \%)$ & - \\
\hline Amiodarone & $59(3.1 \%)$ & $33(1.5 \%)$ & - \\
\hline Others & $109(5.6 \%)$ & $166(7.8 \%)$ & $4(15.4 \%)$ \\
\hline$(-)$ & $1,467(75.9 \%)$ & $1,713(80.3 \%)$ & $20(76.9 \%)$ \\
\hline Total & $1,932(100.0 \%)$ & $2,134(100.0 \%)$ & $26(100.0 \%)$ \\
\hline \multicolumn{4}{|c|}{ Anti-coagulant (warfarin) } \\
\hline$(+)$ & $506(26.2 \%)$ & $231(10.8 \%)$ & $4(15.4 \%)$ \\
\hline$(-)$ & $1,426(73.8 \%)$ & $1,903(89.2 \%)$ & $22(84.6 \%)$ \\
\hline Total & $1,932(100.0 \%)$ & $2,134(100.0 \%)$ & $26(100.0 \%)$ \\
\hline \multicolumn{4}{|l|}{ Anti-platelet agents } \\
\hline$(+)$ & $477(24.7 \%)$ & $309(14.5 \%)$ & $10(38.5 \%)$ \\
\hline Aspirin & $353(18.3 \%)$ & $212(9.9 \%)$ & $5(19.3 \%)$ \\
\hline Ticlopidine & $88(4.6 \%)$ & $68(3.2 \%)$ & $3(11.5 \%)$ \\
\hline Others & $36(1.9 \%)$ & $29(1.4 \%)$ & $2(7.7 \%)$ \\
\hline$(-)$ & $1,455(75.3 \%)$ & $1,825(85.5 \%)$ & $16(61.5 \%)$ \\
\hline Total & $1,932(100.0 \%)$ & $2,134(100.0 \%)$ & $26(100.0 \%)$ \\
\hline
\end{tabular}

\section{Gender-Related Differences}

The male-to-female ratios were 2.6 and 2.3 for DCM and HCM, respectively, and the higher prevalence of these cardiomyopathies in men suggests gender-related responses to various stimuli, including the direct effects of sex hormones ${ }^{26} \mathrm{X}$-chromosome-linked mutations may also explain such gender-related differences, 27 although that would be expected to increase the prevalence of the disorders in women. The surveying method used in the present study, limited to individuals who visited hospitals, may have biased the prevalence measured in men vs women.

\section{Other Cardiomyopathies}

The prevalence of each of the other cardiomyopathies was lower than DCM and HCM. The estimated patient numbers in Japan and prevalence per 100,000 individuals, respectively, were 300 and 0.2 for $\mathrm{RCM}^{10} 520$ and 0.4 for ARVD, 640 and 0.5 for mitochondrial disease, 150 and 0.1 for Fabry's disease of the heart, and 1,000 and 0.8 for prolonged Q-T interval syndrome, from another series of surveys conducted during the same period $!^{1}$ The distribution of the patients with prolonged Q-T interval syndrome by age was distinctive, with the majority of patients being younger than 40 years old. The early onset of this disease with obvious ECG abnormalities and clinical symptoms may be the cause, but the number of patients analyzed was too small to draw definitive conclusions. Few epidemiologic studies of ARVD, mitochondrial disease, Fabry's disease of the heart or prolonged Q-T interval syndrome have been conducted in Japan and despite its methodologic limitations, the results of the nationwide survey described here have provided important information regarding these disorders.

\section{Cardiomyopathies and Long-Term Survival}

According to the 1983 report by the Research Committee on Idiopathic Cardiomyopathy of the Ministry of Health and Welfare of Japan, the respective 5- and 10-year survival rates are $54.3 \%$ and $36.0 \%$ for DCM, and $91.5 \%$ and $81.8 \%$ for $\mathrm{HCM}^{28}$ The present study does not provide precise information on the prognosis of patients with cardiomyopathies because it did not analyze the long-term survival of the participants. However, nearly $50 \%$ of DCM patients were clinically improved, suggesting a better prognosis than 2 decades ago, perhaps, in part, because of the widespread use of ACE inhibitors and $\beta$-adrenergic blockers in the treatment of CHF. Long-term follow-up of the patients 
reported in the present study would reveal the prognosis of DCM patients on contemporary medical treatment.

\section{Laboratory Testing}

The data from the laboratory examinations recorded in this nationwide survey has helped to characterize Japanese patients with cardiomyopathies. Nonsustained ventricular tachycardia and chronic or paroxysmal atrial fibrillation were common in patients with either DCM or HCM. On echocardiography, mitral and tricuspid regurgitation were often present in DCM patients, and LV diastolic dysfunction was frequently observed in either group of patients. Among patients with HCM, approximately 50\% had asymmetric septal hypertrophy on echocardiography, and apical hypertrophy was not uncommon. Angiographically significant coronary artery stenoses were occasionally encountered, though the investigators did not consider these to be the cause of ischemic cardiomyopathy. On histologic examinations, myocyte hypertrophy and myocardial fibrosis were common findings in both DCM and HCM patients, although not all patients underwent endomyocardial biopsies. Mononuclear cellular infiltration, often found in the myocardium of DCM, was not a specific finding, as it was also observed in some cases of HCM. A decreased myocardial ${ }^{201} \mathrm{Tl}$ uptake was common to both DCM and HCM, whereas an abnormal pattern of uptake was a more regular finding in DCM. Thus, abnormalities of ${ }^{201} \mathrm{Tl}$-scintigraphy seem to be a sensitive marker of myocardial injury in both DCM and HCM 29,30 Objective parameters that are easily measurable are needed to follow disease activity and monitor the effects of treatments. Plasma BNP concentration may be one such sensitive parameter, although it increases in most patients with $\mathrm{CHF}$, regardless of etiology and is not specific for DCM ${ }^{31}$ In this study, the plasma BNP level was abnormally high in $>90 \%$ of DCM patients, suggesting that it may be useful for monitoring the patient's clinical course 32

This epidemiologic survey also examined the association between viral hepatitis and cardiomyopathies, a recently established pathogenetic mechanism of cardiomyopathies?3,34 Seropositivity for HCV antibody was detected in a greater percentage of patients with DCM or HCM relative to prevalence of positive HCV antibody in healthy, age-matched voluntary first blood donors in Japan: the prevalence was $1.65 \%$ in subjects $45-49$ years of age and $2.41 \%$ in subjects 55-59 years of age (data from the Japan Red Cross Blood Center, 1990). Consistent with previous observations, positive HCV antibody serology was found more often among patients with HCM than with DCM 34 In contrast, positivity for serum hepatitis B antigen in patients with cardiomyopathies and age-matched first blood donors in Japan Red Cross Blood Center (1.2\%) was comparable, confirming that the high prevalence of HCV antibody positivity in patients with cardiomyopathies was not caused by biased blood sampling.

\section{Medical Management}

ACE inhibitors, $\beta$-adrenergic blockers and digitalis, in that order, were the commonly used drugs among patients with DCM identified in this survey. Carvedilol was the most frequently prescribed $\beta$-adrenergic blocker, possible because of favorable reports of their efficacy 35,36 In patients with HCM, the use of $\beta$-adrenergic vs calcium channel blockers was balanced. $\beta 1$-selective adrenergic blockers were used more frequently than non-selective agents. In contrast to patterns recommended in Western countries, class I antiarrhythmic agents, as opposed to class III drugs, were used more frequently in this Japanese patient population, but the reports showing the superiority of class III antiarrhythmic drugs in the treatment of $\mathrm{CHF}$ patients are likely to soon change this choice in Japan37,38 Anticoagulants and antiplatelet drugs were regularly used for the treatment of DCM and the prescription of these classes of drugs was balanced in patients with HCM, though less frequent than in patients with DCM.

\section{Study Limitations}

A primary limitation is the patient populations analyzed in each survey. This study was conducted as hospital-based surveys and analyzed the responses to the questionnaires about cardiomypathy patients in hospitals. Thus, the target populations consist of patients with any medical problems. This study design can lead to an underestimation of the prevalence of cardiomyopathies because of the selection bias: an undetermined number of asymptomatic subjects may not have been included in the analysis. A significant number of HCM patients, in particular those with apical HCM, do not have any subjective symptoms and may not be included in target populations of a hospital-based survey if they are not detected by ECG or chest X-ray abnormality during routine checkups. However, because populationbased group checkups using ECG and chest X-ray examinations are now routinely performed for all nations in Japan from childhood, asymptomatic patients with cardiomyopathies showing abnormal ECG or cardiomegaly are recommended to undergo further examinations in a hospital. Therefore, this study will probably have included these asymptomatic subjects and underestimation may be less than in previous hospital record-based studies.

Nevertheless, there still remains a possibility of underestimating the prevalence of cardiomyopathies by overlooking asymptomatic subjects with normal ECG and chest $\mathrm{X}$-ray findings, such as patients with early stage DCM. Such patients may survive longer after first diagnosis than symptomatic patients because they are at an earlier disease stage and thus, the underestimation will also bias the evaluation of the prognosis of DCM.

Hospital-based surveys can also have another selection bias because those cardiologists who have more interest in cardiomyopathies may actively respond to the questionnaires compared with those whose specialty is not cardiomyopathies. The proportion of patients with cardiomyopathies to the total patients may be higher for the former than the latter and can result in overestimating the prevalence of cardiomyopathies.

This study surveyed a number of hospitals and the data from clinical examinations such as echocardiography were obtained by a number of different observers and by local interpretation, inter-institution as well as inter-observer variability could affect the precision of the data. Theoretically, the inaccuracy would be reduced by having one trained operator at a site, multiple measurements, and more than one reader for each echocardiogram.

The prevalence of ARVD, mitochondrial disease, Fabry's disease of the heart and prolonged Q-T interval syndrome might have been overestimated because inappropriate cases such as duplicate cases were not excluded from the analysis of the patients with these myocardial diseases. Nevertheless, the overestimation of the prevalence should be negligible because we followed the manual prepared by the Epidemiology of Intractable Diseases Research Committee of the 
Ministry of Health and Welfare of Japan!11,14

\section{Conclusions}

In summary, the results of a nationwide Japanese survey of patients with DCM, HCM, RCM, ARVD and other cardiomyopathies has yielded important current epidemiologic and clinical information on the characteristics of these disorders in Japan. Detailed analyses of the results will likely contribute to a better understanding and thus progress in the diagnosis and therapy of patients with cardiomyopathies. Serial follow up surveys will collect additional information on the prognosis and optimal management of these patients.

\section{Acknowledgment}

The authors are grateful to the physicians who made essential contributions to this study by kindly replying to the surveys' questionnaires.

This study was supported in part by a Grant-in-Aid for Idiopathic Cardiomyopathy Research Committee and a Grant-in-Aid for the Epidemiology of Intractable Diseases Research Committee from the Ministry of Health and Welfare of Japan.

\section{References}

1. 1999 Heart and Stroke Statistical Update. Dallas, TX: American Heart Association; 1998.

2. Richardson P, McKenna W, Bristow M, Maisch B, Mautner B, O'Connell J, et al. Report of the 1995 World Health Organization/ International Society and Federation of Cardiology task force on the definition and classification of cardiomyopathies. Circulation 1996; 93: $841-842$.

3. Arbustini E, Diegoli M, Morbini P, Dal Bello B, Banchieri N, Pilotto A, et al. Prevalence and characteristics of dystrophin defects in adult male patients with dilated cardiomyopathy. J Am Coll Cardiol 2000; 35: $1760-1768$.

4. Watkins H, McKenna WJ, Thierfelder L, Suk HJ, Anan R, O'Donoghue A, et al. Mutations in the genes for cardiac troponin T and alpha-tropomyosin in hypertrophic cardiomyopathy. $N$ Engl $J$ Med 1995; 332: $1058-1064$.

5. Matsumori A. Molecular and immune mechanisms in the pathogenesis of cardiomyopathy: Role of viruses, cytokines and nitric oxide. Jpn Circ J 1997; 61: 275-291.

6. Taliercio CP, Seward JB, Driscoll DJ, Fisher LD, Gersh BJ, Tajik AJ. Idiopathic dilated cardiomyopathy in the young: Clinical profile and natural history. J Am Coll Cardiol 1985; 6: 1126-1131.

7. Sugrue DD, Rodeheffer RJ, Codd MB, Ballard DJ, Fuster V, Gersh BJ. The clinical course of idiopathic dilated cardiomyopathy. A population-based study. Ann Intern Med 1992; 117: 117-123.

8. Hori M, Yamamoto K, Kodama K, Takashima S, Sato H, Koretsune Y, et al. Successful launch of cardiac transplantation in Japan. Osaka University Cardiac Transplant Program. Jpn Circ J 2000; 64: 326332.

9. Kitamura S, Nakatani T, Yagihara T, Sasako Y, Kobayashi K, Kobayashi J, et al. Cardiac transplantation under new legislation for organ transplantation in Japan: Report of two cases. Jpn Circ J 2000; 64: $333-339$.

10. Miura K, Nakagawa H, Morikawa Y, Sasayama S, Matsumori A, Hasegawa K, et al. Epidemiology of idiopathic cardiomyopathy in Japan: Results from a nationwide survey. Heart 2002; 87: 126-130.

11. Ohno Y, editor. Annual Report of the Research Committee on Epidemiology of Un-registered Intractable Diseases in Japan. Ministry of Health and Welfare of Japan, Japan. 2000: 680-707 (in Japanese).

12. Research Committee on Idiopathic Cardiomyopathy, the Ministry of Health and Welfare, Japan. Guidelines for the diagnosis of idiopathic cardiomyopathy. In: Annual Report of the Research Committee on Idiopathic Cardiomyopathy, the Ministry of Health and Welfare, Japan. 1985: 13-15 (in Japanese).

13. The WHO/ISFC task force on the definition and classification of cardiomyopathies. Report of the WHO/ISFC task force on the definition and classification of cardiomyopathies. Br Heart J 1980; 44: $672-673$.

14. Tamakoshi A. The procedure in the nationwide epidemiological survey of an intractable disease. In: Ohno Y, editor. The manual for nationwide epidemiological survey of intractable diseases. The
Research Committee on Epidemiology of Intractable Diseases, Nagoya, Japan. 1994: 5-11 (in Japanese).

15. Hattori Y, Nakano T, Hattori J, Sawada J, Sakai K. Epidemiology of idiopathic cardiomyopathies (the 4th. report). In: Annual report of the Research Committee on Idiopathic Cardiomyopathy, the Ministry of Health and Welfare, Japan. 1977: 10-15 (in Japanese).

16. Raker S, Sinagra G, Di Lenarda A, Poletti A, Bussani R, Silvestri F, et al. Epidemiology of dilated cardiomyopathy: A prospective postmortem study of 5252 necropsies. The Heart Muscle Disease Study Group. Eur Heart J 1997; 18: 117-123.

17. Maron BJ, Gardin JM, Flack JM, Gidding SS, Kurosaki TT, Bild DE. Prevalence of hypertrophic cardiomyopathy in a general population of young adults: Echocardiographic analysis of 4111 subjects in the CARDIA study. Circulation 1995; 92: 785-789.

18. Agarwal AK, Venugopalan P, Meharali AK, de Debono D. Idiopathic dilated cardiomyopathy in an Omani population of the Arabian Peninsula: Prevalence, clinical profile and natural history. Int $J$ Cardiol 2000; 75: 147-159.

19. Kuroda T, Shiina A, Tsuruda K, Fujita T, Yamasawa M, Mitsuhashi $\mathrm{T}$, et al. Mass screening of cardiovascular disorders by two-dimensional echocardiography. J Cardiol 1989; 19: 933-943 (in Japanese).

20. Kibira S, Miura M. Epidemiology of dilated cardiomyopathy and hypertrophic cardiomyopathy. Nippon Rinsho 2000; 58: 141-146 (in Japanese).

21. Williams DG, Olson EG. Prevalence of overt dilated cardiomyopathy in two regions of England. Br Heart J 1985; 54: 153-155.

22. Codd MB, Sugrue DD, Gersh BJ, Melton LJ. Epidemiology of idiopathic dilated and hypertrophic cardiomyopathy: A population-based study in Olmsted County, Minnesota, 1975-1984. Circulation 1989; 80: $564-572$.

23. Lilienfeld DE, Sprafka JM, Pham DL, Baxter J. Morbidity from congestive and hypertrophic cardiomyopathy in the Minneapolis-St. Paul metropolitan area: 1979-1984. Cardiology 1992; 80: 71-76.

24. Hada Y, Sakamoto T, Amano K, Yamaguchi T, Takenaka K, Takahashi $\mathrm{H}$, et al. Prevalence of hypertrophic cardiomyopathy in a population of adult Japanese workers as detected by echocardiographic screening. Am J Cardiol 1987; 59: 183-184.

25. Agnarsson UT, Hardarson T, Hallgrimsson J, Sigfusson N. The prevalence of hypertrophic cardiomyopathy in men: An echocardiographic population screening study with a review of death records. $J$ Intern Med 1992; 232: 499-506.

26. Berko BA. Gender-related differences in cardiomyopathy. Cardiovasc Clin 1989; 19: 285-300

27. Mestroni L, Giacca M. Molecular genetics of dilated cardiomyopathy. Curr Opin Cardiol 1997; 12: 303-309.

28. Kawai C, Sakurai T, Kishimoto C, Tomioka N. A follow up survey for the prognosis of idiopathic cardiomyopathies in Japan. In: Annual report of the Research Committee on Idiopathic Cardiomyopathy, the Ministry of Health and Welfare, Japan. 1983: 63-66 (in Japanese).

29. Li LX, Nohara R, Okuda K, Hosokawa R, Hata T, Tanaka M, et al. Comparative study of ${ }^{201} \mathrm{Tl}$-scintigraphic image and myocardial pathologic findings in patients with dilated cardiomyopathy. Ann Nucl Med 1996; 10: 307-314.

30. Beller GA. Diagnostic accuracy of thallium-201 myocardial perfusion imaging. Circulation 1991; 84(Suppl): I-1-I-6.

31. Omland T, Aakvaag A, Bonarjee VVS, Caidahl K, Lie RT, Nilsen DWT, et al. Plasma brain natriuretic peptide as an indicator of left ventricular systolic function and long-term survival after acute myocardial infarction: Comparison with plasma atrial natriuretic peptide and N-terminal proatrial natriuretic peptide. Circulation 1996; 93: $1963-1969$

32. Tsutamoto T, Wada A, Maeda K, Hisanaga T, Maeda Y, Fukai D, et al. Attenuation of compensation endogenous cardiac natriuretic peptide system in chronic heart failure: Prognostic role of plasma brain natriuretic peptide concentration in patients with chronic symptomatic left ventricular dysfunction. Circulation 1997; 96: 509-516.

33. Matsumori A, Matoba Y, Sasayama S. Dilated cardiomyopathy associated with hepatitis C virus infection. Circulation 1995; 92: 25192525.

34. Matsumori A, Matoba Y, Nishio R, Shioi T, Ono K, Sasayama S. Detection of hepatitis $\mathrm{C}$ virus RNA from the heart of patients with hypertrophic cardiomyopathy. Biochem Biophys Res Commun 1996; 222: $678-682$

35. Packer M, Bristow MR, Cohn JN, Colucci WS, Fowler MB, Gilbert EM, et al. The effect of carvedilol on mobidity and motality in patients with chronic heart failure. U.S. Carvedilol Heart Failure Study Group. N Engl J Med 1996; 334: 1349-1355.

36. Metra M, Giubbini R, Nodari S, Boldi E, Modena MG, Dei Cas L. Differential effects of beta-blockers in patients with heart failure: A 
prospective, randomized, double-blind comparison of the long-term effects of metoprolol versus carvedilol. Circulation 2000; 102: 546 551.

37. Doval HC, Nul DR, Grancelli HO, Perrone SV, Bortman GR, Curiel $\mathrm{R}$. Randomized trial of low-dose amiodarone in severe congestive heart failure. Group de Estudio de la Sobrevida en la Insuficiencia Cardiaca en Argentina (GESICA). Lancet 1994; 344: 493-498.

38. Naccarelli GV, Wolbrette DL, Patel HM, Luck JC. Amiodarone: Clinical trials. Curr Opin Cardiol 2000; 15: 64-72.

\section{Appendix}

Co-research workers are as follows.

Gifu University: Hisayoshi Fujiwara, MD; International Medical Center of Japan: Michiaki Hiroe, MD; Osaka University: Masatsugu Hori, MD;
Kurume University: Tsutomu Imaizumi, MD; Tokai University: Hidetoshi Inoko, $\mathrm{PhD}$; Kitasato University: Tohru Izumi, MD; Juntendo University: Sachio Kawai, MD; Tokyo Women's Medical College: Masatoshi Kawana, MD; Tokyo Medical and Dental University: Akinori Kimura, MD; Hokkaido University: Akira Kitabatake, MD; National Cardiovascular Center: Soichiro Kitamura, MD; Osaka Medical College: Yasushi Kitaura, MD; Yamaguchi University: Masunori Matsuzaki, MD; University of Tokyo: Ryozo Nagai, MD; Keio University: Satoshi Ogawa, MD; Shimane Medical College: Toshio Shimada, MD; Kyoto University: Kunitada Shimotohno, MD; Jikei University: Nobuakira Takeda, MD; Osaka University: Keiko Takihara, MD; Gifu International Institute of Biotechnology: Masashi Tanaka, MD; Kagoshima University: Chuwa Tei, MD; University of Tokyo: Teruhiko Toyo-oka, MD; University of Tsukuba: Iwao Yamaguchi, MD; Kobe University: Mitsuhiro Yokoyama, MD; National Cardiovascular Center: Chikao Yutani, MD. 